\title{
RHEOLOGICAL PROPERTIES OF WATERMELON JUICE AS AFFECTED BY CONCENTRATION
}

\author{
${ }^{1}$ Yosefzadeh Sani, S., ${ }^{2 *}$ Sharifi, A., ${ }^{1}$ Mortazavi, S.A.
}

${ }^{1}$ Department of Food Science and Technology, Sabzevar Branch, Islamic Azad University, Sabzevar, Iran

${ }^{2}$ Department of Food Science and Technology, Faculty of Industrial and Mechanical Engineering, Qazvin Branch, Islamic Azad University, Qazvin, Iran.

*Corresponding author email: asharifi@qiau.ac.ir

Tel: +989127335291, Fax: +982833665279

Received: $8^{\text {th }}$ November $2016 \quad$ Revised: $19^{\text {th }}$ March $2018 \quad$ Accepted:21 ${ }^{\text {st }}$ March 2018

DOI: https://doi.org/10.22452/mjs.vol37no1.1

\begin{abstract}
Rheological properties are presented based on the flow behavior and the deformation of a substance by the action of stress. Among the juices, watermelon is very popular and also very nutritious. In this research, the flow behavior of watermelon juice was determined at concentrations of 40, 50 and $60{ }^{\circ} \mathrm{Brix}$ and temperatures of 15,20 and $30{ }^{\circ} \mathrm{C}$. Shear stress data obtained from juices were fitted with rheological models including Newtonian, power law. Also, concentration relation and temperature was determined by Arnius model and exponential law models. Based on the results obtained, both temperature and concentration decreased $n$ values but increased $\mathrm{K}$ values. The power law model was also able to predict the dependence on apparent viscosity with concentration with high precision. The combined Arnius-power law model showed a high compliance for the effect of concentration-temperature on the apparent viscosity. It can be concluded that the temperature and concentration completely affect the rheological properties of Iranian watermelon juices
\end{abstract}

Keywords: Concentration, Juice, Rheological properties, Watermelon

\section{INTRODUCTION}

In recent years, extensive studies have been carried out on identifying healthy foods and tried to make them as the product of processing, which increases the utility and acceptance of the consumer. Meanwhile, watermelon juice, which has many properties, including antimicrobial, anticonvulsant and anti-inflammatory. (Kim et al., 2010).

Although exports of various types of watermelon showed $21 \%$ growth compared to the same period of the previous year, the share of exports in this sector decreased to $0.4 \%$. Watermelon juice has the highest global market in terms of production, having different vitamins and also rich in potassium ion. (chuah et al., 2008). Watermelon juice is rich in minerals and vitamins such as vitamins $\mathrm{A}, \mathrm{B}, \mathrm{C}$, potassium, iron, calcium, manganese, zinc, antioxidants, and other nutrients. (Keshani et al., 2012).

Among the export items, over the past decade, Iran with the annual production of more than 2 million and 200 thousand tons of watermelon was in fourth place in the world. . The product has been planted in four seasons, and more than 100,000 tons of watermelon has been exported to Iraq, the United Arab Emirates and Kuwait annually. (Mohammadi sani et al., 2013). 
Juices are condensed with evaporative condensation, freezing and osmotic methods. (Maskon, 2006). The evaporation method is superior to many other methods because of the possibility of achieving higher concentrations, higher production capacity and being economical to rheological knowledge, (Guno et al., 2006). Examining the rheological properties of food can provide a great deal of information about how to change their structure when they are subjected to the properties of different processes. (Quek et al., 2007).

The juice production industry is one of the industries that plays an important role in the food industry, and it is important to provide product with high quality in order to achieve effective competition. (Dak et al., 2007).

The rheological properties of fruit juices and their concentrates are of great importance for devising design, the transfer of materials and also flavor. (Hanil et al., 2014).

According to published data, nearly 564 million kilograms, equivalent to 126 million and 578 thousand dollars of watermelon has exported to countries such as Georgia, Azerbaijan, Albania, Germany, Russia, Hungary, Netherlands, Nevada, Poland, Kuwait, in 2014, global. China accounted for $67 \%$ of the total production in the world. They had the next rank with less than $4 \%$ of the world's production of Turkey, Iran, Brazil and Egypt. (Grato et al., 2002; Guala et al., 2011).

Watermelon has an amino acid called citrulline and substances called carotene, lycopene, and mannitol. (Azoubel et al., 2005).

Watermelon like tomatoes containing large amounts of lycopene, organic pigments from carotene materials (Alami et al., 2012). These materials, which are considered to be antioxidants, neutralize active molecules called free radicals that produce chemical reactions in the body for developing of diseases such as cancer. (Cabral et al., 2007).

Depending on the different factors such as concentration, temperature, or lack of a clear process, fruit extracts can have different rheological behavior such as Newtonian, Psodo plastic, plastic and Thixotropic. On the other hand, finding an appropriate model for describing their rheological behavior can lead to a reduction in experimental experiments and the design of processes and devices. (Ahmed, 2004).

Considering the importance of rheological behavior of fruit juices, the purpose of this study is to model shear flow behavior of Iranian watermelon juices which concentrate (40-60 Brix) at 15,20 and $30^{\circ} \mathrm{C}$.

\section{MATERIAL AND METHODS}

\section{Material}

In this research, Persian watermelon was prepared from Mashhad market.

They were washed with water to remove waste materials. Surface water was dried with a clean cloth and then cut into lengthwise sections with a knife. Dewatering was done through Electric Juicer (Toshiba -Model JC-17E) made in Japan. Then by using a vacuum system, juice was clarified.

Protein: Protein content was done with using the Kjeldahl method (AOAC, 2000).

Fat: was determined by the method described in $\operatorname{AOAC}(2000) 0$

Carbohydrate: was determined by the method described in AOAC( 2000.)

\section{Sample Preparation}

$100 \mathrm{~g}$ of sample was poured into the balloon and was heated at $70^{\circ} \mathrm{C}$. The sample was placed inside the evaporator chamber. The water 
of watermelon was taken and in 3 stages the product was concentrated from 40 to $60^{\circ} \mathrm{Brix}$. Then, stored at $4{ }^{\circ} \mathrm{C}$ until analysis (Mohammadi Sani et al).

Total soluble solid evaluation (TSS) (Brix) Brix was determined with refractometer (Atago Rx-7000a, Tokyo, Japan)

Moisture content (dry basis); was determined by drying the samples in an oven (MX-50 model (A\&D Co., Limited, Tokyo, Japan) at $105{ }^{\circ} \mathrm{C}$ for $24 \mathrm{~h}$ (AACC, 2000).

PH: $\mathrm{pH}$ was determined by $\mathrm{pH}$ meter (HORIBA, F12, and Japan) (AOAC, 2000).

\section{Determination of density}

The empty and dry pycnometer was weighed down to a specified volume $(25 \mathrm{cc})$. Then, filled with the desired liquid and weighed while the outer wall was dry. The difference between the weight of the empty pycnometer

$$
\begin{gathered}
\mathrm{k}=\mathrm{A} * \exp _{\mathrm{a}}^{(-\mathrm{E} / \mathrm{RT})} \\
\text { Ln } \mathrm{k}=\mathrm{Ln} \cdot \mathrm{A}-\frac{\mathrm{Ea}}{R T} \\
\text { Ln } \mu=\text { Ln. } \mu_{\infty}+\frac{\mathrm{Ea}}{R T}
\end{gathered}
$$

The consistency coefficient changes were indicated as a function of temperature with the Arrhenius equation.

After taking the natural logarithm of both sides, a linear equation is taken as the following form: where the rate constant is $k, T$ is the absolute temperature (in kelvins), $\mathrm{A}$ is the pre-exponential factor (or simply the pre factor), $E_{a}$ is the activation energy, and $R$ is the universal gas constant: $\mathrm{R}$ has the value of $8.314 .10^{-3} \mathrm{~kJ}$

$$
\begin{aligned}
& \tau=\mu \gamma \\
& \tau=k \cdot \gamma^{n} \\
& \tau=t .+k \cdot \gamma^{n}
\end{aligned}
$$

and the pycnometer was filled with desired liquid weight. By dividing it with the volume of the pycnometer container, the density of the liquid at a given temperature was achieved (Mohammadi Sani et al).

\section{Rheological parameters}

The behavior of shear flow of Iranian watermelon juice was determined at the concentrations mentioned at a temperature of 15 , 20 and $30^{\circ} \mathrm{C}$ through a US rotating instrument Brockfield viscometer. Results were analyzed using rheological models. All rheological tests were performed in two replications and the average results were reported (Mohammadi Sani et al).

Effect of temperature on the consistency coefficient (Arrhenius equation)

The Arrhenius equation is a formula for the temperature dependence of reaction rates:

$\mathrm{mol}^{-1} \mathrm{~K}^{-1}$. By plotting linear variations $\mathrm{Ln} \mathrm{K}$ against the temperature and obtaining slope and width from the source, $E_{\mathrm{a}}$ and A were calculated respectively(Steff, 1996).

The flow behavior associated with the shear rate of Iranian fruit samples can be defined using the following rheological models (e.g. Newtonian (2), Power-Law (3), Herschel-Bulkley (4) equations depending on the nature of the juices (Altan et al., 2005; Belibagli et al., 2007). 


\section{Statistical Analysis}

SPSS software (Version 18) was used to analyze the data .Microsoft Excel 2007was used for rheograms.

\section{RESULT AND DISCUSSION}

Table 1 shows the experimental values for physical properties of watermelon juice.

In Newtonian fluids, the relationship between shear stress and shear rates variations applied linearly, and the constant coefficient of converting this linear fit to the equation is the same as viscosity, but in non-Newtonian fluids, there is no longer any effect of the linear relationship between shear stress variations and the shear rate. In this fluids, the duration of the stress action plays an important role in the shear stress achieved. Consequently, in nonNewtonian fluids, a constant coefficient of viscosity is not meaningful way for describing the shear stress state. Non-Newtonian fluids are divided into three groups' independent of time, time dependent and viscoelastic (Gratao et al., 2002).

Table 1. Experimental values for physical properties of watermelon juice

\begin{tabular}{lcccc}
\hline $\mathrm{T}\left({ }^{\circ} \mathrm{C}\right)$ & $\mathrm{C}\left({ }^{\circ}\right.$ Brix $)$ & $\begin{array}{c}\text { Moisture } \\
\text { content }(\%, \\
\text { w.b })\end{array}$ & $\mathrm{pH}$ & Density $\left(\mathrm{kg} / \mathrm{m}^{3}\right)$ \\
\hline 15 & 40 & $77.5 \pm 0.01$ & 4.1 & 1.189 \\
& 50 & $66.5 \pm 0.01$ & 4.3 & 1.268 \\
& 60 & $55.0 \pm 0.02$ & 5 & 1.345 \\
20 & & & 1.179 \\
& 40 & $64.80 \pm 0.01$ & 4.9 & 1.240 \\
& 50 & $53.60 \pm 0.02$ & 4.8 & 1.331 \\
30 & 60 & $42.30 \pm 0.01$ & 5.6 & 1.165 \\
& & & \\
& 40 & $41.0 \pm 0.02$ & 4.2 & 1.210 \\
& 50 & $41.1 \pm 0.01$ & 5.5 & \\
\hline
\end{tabular}

The slope of the stress- strain curve at high shear intensities is referred to as the viscosity at infinite cutting and at low shear intensities to zero viscosity. In these materials, the rate of increase in stress versus the severity of the cutting is somewhat negative (viscosity is a descending function of the severity of the cutting). In other words, if the power law model is used as the base law for pseudo plastic materials, then $\mathrm{n}$ will be smaller than one. (Steffe, 1996).Table 2 shows the rheological properties of watermelon juice by the Power- 
Law. As the flow tables show, with increasing shear velocity, the tangent tangency of graph decreases at each point of the strain, which demonstrates the presence of pseudo plastic for the fruit juices tested. This issue is further elucidated by the results of rheological modeling of the behavior of the Iranian water shear flow. As it can be seen, the Newtonian flow behavior index decreases with increasing temperature in a particular brix. For example, the consistency decreased by increasing the temperature from 15 to $30^{\circ} \mathrm{c}$. On the other hand, the results showed that increasing the brix at a specific temperature increased consistency. These results were fully expected because the temperature increase due to the increase in the molecular movement reduced the viscosity, and on the other hand, with increasing solids content of the bubble solution, the viscosity was also high. In a particular brix, the index of current behavior increases with increasing temperature, in other words, the amount of pseudo plastic of flow behavior decreases.

Table 2. Parameters consistency (K), flow behavior index (n) and Correlation Coefficient (R2) for powerlaw model

\begin{tabular}{lcccc}
\hline $\mathrm{T}\left({ }^{\circ} \mathrm{C}\right)$ & $\mathrm{C}\left({ }^{\circ}\right.$ Brix $)$ & $\mathrm{K}\left(\mathrm{pa} . \mathrm{s}^{\mathrm{n}}\right)$ & $n$ & $R^{2}$ \\
\hline 15 & & & 0.899 \\
& 40 & 0.195 & 0.955 & 0.958 \\
& 50 & 1.405 & 0.924 & 0.880 \\
& 60 & 3.460 & 0.913 & \\
& & & 0.939 \\
20 & & & 0.997 \\
& 40 & 0.180 & 0.933 & 0.968 \\
& 50 & 0.360 & 0.821 & 0.896 \\
30 & 60 & 2.030 & 0.982 & 0.999 \\
& & & 0.924 & 0.975 \\
& 40 & 0.150 & 0.912 & \\
\hline
\end{tabular}

The same results were also obtained by other scientists in various fruit juices, such as keshani et al., 2010, which stated, power law and Herschel Balkil models described better Pomelo's behavior than Bingham and Casson models in high concentration. Also Goula et al., 2011, examined the rheological properties of kiwifruit juice. The rheological properties of pineapple juice were studied by Dak et al., 2008 at different concentrations. As a result, the increase in temperature and concentration influenced the behavioral index of power law model. Dak et al., 2006 studied the rheological properties of mango juice. The findings from the researchers were similar to those in blackberry juice" and mango juice (Cabral et al., 2007; Dak et al., 2006). According to Sharma et al $s$ (1996) findings, pectin plays a major role in the viscosity. Several reports have shown the influence of Brix and the coefficient of consistency at different juices like, orange juice, pineapple juice, pomegranate juice and cherry 
juice (Ibarz et al., 1989; Shamsudin et al., 2007; Kaya et al., 2005; Juszczak et al., 2004).

The best fitting model have been reported by researchers (Ibarz et al., 2009; Ramos and Ibarz, 1998; Goula et al., 2011) in juices like pear, peach, orange and pineapple.

Evaluation of Temperature relevance with stability Coefficient

Temperature, according to literature, is known to have an inversely proportional relationship with the viscosity of liquids .reduction in the flow resistance lead to increase in flow ability (Hanil et al., 2014) .Experimental results revealed that temperature affected the viscosity of juices. For the shear rate range considered, the viscosity of the juice decreased as temperature increased.
Arrhenius model was used to determine the stability coefficient, $K_{0 T}$ and $E_{a}$, vales were achieved using linear regression. Table 3 shows the stability coefficient, $E_{a}$, and correlation coefficient with different temperatures for watermelon juice. As can be seen, the activation energy increases with increasing concentration. As it shown in table 3 at first in $40^{\circ}$ Brix $E_{a}$ vales was 28.80. Experimental values of Stability coefficient $\mathrm{k}$, varied from $0.01232-0.0018 \mathrm{~Pa} \mathrm{~s}^{\mathrm{n}}$ and $R^{2}$ from 0.996 to 0.972 .

The values of the parameters obtained from Arrhenius model were obtained by linear regression analysis and are tabulated in Table 3. These values of activation energy for the juices were significantly higher when the brix was increased.

Table 3. The Stability Coefficient $\left(\mathrm{K}_{0} \mathrm{~T}\right)$, Activation energy (Ea), Correlation Coefficient (R2), with different temperatures for watermelon juice

\begin{tabular}{lccc}
\hline${ }^{\circ}$ Brix & $K_{\text {OT }}\left(\right.$ pa.s $\left.^{n}\right)$ & $E_{a .}(\mathrm{kJ} / \mathrm{mol})$ & $R^{2}$ \\
\hline 40 & & & 0.996 \\
50 & 0.012321 & 28.80 & 0.954 \\
60 & 0.010031 & 30.070 & 0.972 \\
\hline \hline
\end{tabular}

The Ea values corresponding to mentioned Brix numbers were 28.80, 30.07, $34.72 \mathrm{~kJ} / \mathrm{mol}$, respectively. The activation energy calculated by this method is consistent with Mohammadi sani et al (2013).
The Experimental values of concentrated watermelon juice in ${ }^{\circ}$ Brix 40, 50, 60 at different temperature are shown in table 4. It indicates increasing stress can caused to viscosity reduction. 
Table 4. Experimental values of concentrated watermelon juice in ${ }^{\circ}$ Brix 40,50 and 60 at different temperature

\begin{tabular}{ccccc}
\hline $\mathrm{T}\left({ }^{\circ} \mathrm{C}\right)$ & ${ }^{\circ}$ Brix & $\begin{array}{c}\text { Shear rate } \\
\left(\mathrm{s}^{-1}\right)\end{array}$ & $\begin{array}{c}\text { Apparent } \\
\text { viscosity (pa.s) }\end{array}$ & $\begin{array}{c}\text { Shear } \\
\text { stress(pa) }\end{array}$ \\
\hline 15 & 40 & $9.1-370$ & $0.020-0.225$ & \\
\hline & 50 & $9.1-350$ & $0.015-0.327$ & $1.56-760$ \\
& 60 & & $0.014-0.357$ & $2.51-810$ \\
& & & \\
& & & & \\
& 40 & $9.1-350$ & $0.028-0.217$ & $1.67-750$ \\
& 50 & $9.2-330$ & $0.018-0.347$ & $2.50-880$ \\
& 60 & $9.3-330$ & $0.014-0.387$ & $3.33-890$ \\
& & & & \\
& 40 & $9.1-350$ & $0.035-0.237$ & $1.67-780$ \\
& 50 & $9.2-340$ & $0.028-0.337$ & $3.69-960$ \\
& 60 & $9.4-340$ & $0.015-0.397$ & $4.10-980$ \\
\hline
\end{tabular}

The results showed that total soluble solids content and temperature had effect on the juice viscosity. It also shows the direct effect of concentration and temperature on the viscosity (Mohammadi sani et al., 2013).

\section{CONCLUSION}

Among the models used, power law model had the highest efficiency in predicting the shear flow behavior of Iranian watermelon and the parameters ( $\mathrm{n}$ and $\mathrm{k}$ ) which influenced by temperature and concentration. Study of these changes contributed to the design of fruit juice products with a suitable viscosity. Otherwise, the correct design of the water treatment process can be achieved. The Hybrid-Arnius Law for the expression of concentration-temperature effect on the apparent viscosity had a high correlation that could be used to predict viscosity under the influence of simultaneous concentration and
temperature.Watermelon juice presented pseudoplastic behavior for different concentration and temperature studied $\left(\mathrm{R}^{2>} 0.899\right)$.

\section{REFERENCE}

AACC. (2000). Approved methods of the American Association of Chemist $\left(10^{\text {th }}\right.$ $\mathrm{Ed})$.

AOAC (2000). Official Methods of Analysis Association of Official Analytical Chemists17th Edition.

Ahmed, J. (2004). Rheological behaviour and color changes of ginger paste during storage. International Journal of Food Science and Technology 39: 325-330.

Alami, A., Emam Jome, Z. and Mirzaei, H. (2012). Effect of pressure and temperature of concentration on some of properties of watermelon juice. Journal of Food Science \& Industrial 34 (9): 37 44. 
Altan, A. and Maskan, M. (2005). Rheological behavior of pomegranate (Punica granatum L.) juice and concentrate. Journal of Texture Studies 36(2):68-77.

Azoubel, P.M., Cipriani, D.C., El-Aouar, A.A., Antonio, G.C. and Xidieh Murr, F.E. (2005). Effect of concentration on the physical properties of cashew juice. Journal of Food Engineering 66: 413417.

Belibagli, K.B. and Dalgic, A.C. (2007). Rheological properties of sour-cherry juic and concentrate. International Journal of Food Science and Technology 42 (3):773-776.

Cabral, R.A.F., Orrego-Alzate, C.E., Gabas, A.L. and Telis-Romero, J. (2007). Rheological and thermo physical properties of blackberry juice. Journal of Food Science and Technology 27 (3):589-596.

Chuah, T.G., Keshani, S., Chin, N.L., Lau, M.C. and Chin, D.S.G. (2008). Rheological properties of diluted pummelo juice as affected by three different concentrations. International Journal of Food Engineering 4 (1):30-40.

Dak, M., Verma, R.C. and Jaaffrey, S.N.A. (2007). Effect of temperature and concentration on rheological properties of 'Kesar' mango juice.Journal of Food Engineering 80 (10):11-1015.

Dak, M., Verma, R.C. and Jain, M.K. (2008). Mathematical models for prediction of rheological parameters of pineapple juice. International Journal of Food Engineering 4 (3): 3-7.

Dak, M., Verma, R.C. and Sharma, G. (2006). Flow characteristics of juice of 'Totapuri' mangoes. Journal of Food Engineering 76(1): 557-561.

Goula, A.M. and Adamopoulos, K.G. (2011). Rheological models of kiwifruit juice for processing applications. International
Journal of Food Processing \& Technology 2 (1):20-25.

Gratao, A.C.A., Silveira, V. Jr and TelisRomero, J. (2002). Rheology of soursop juice and friction factors in circular pipe flow. Proceeding of the Mercosur International Conference. System Engineering Board.

Gunko, S., Verbych, S., Bryk, M. and Hilal, N. (2006). Concentration of apple juice using direct contact membrane distillation. Disalination 190: 117-124.

Hanil, M., Zahidah, WZ. Irwani, HS, Saniah, K. (2014). Effects of drying on the physical characteristics of dehydrated watermelon rind candies. Journal of Tropical. Agriculture and food. Science. 42(2):115-123.

Ibarz, A. and Miguelsanz, R. (1989). Variation with temperature and soluble solids concentration of the density of a depectinised and clarified pear juice. Journal of Food Engineering 10 (4):319323.

Ibarz, R., Falguera, V., Garvin, A., Garza, S., Pagan, J. and Ibarz, A. (2009). Flow behavior of clarified orange juice at low temperatures. Journal of Texture Studies 40:445-456.

Juszczak, L. and Fortuna, T (2004). Effect of temperature and soluble solid content on the viscosity of cherry juice concentrate. International Agrophysics 18: 17-21.

Kaya, A. and Sozer, N. (2005). Rheological behavior of sour pomegranate juice concentrates (Punica granatum L.). International Journal of Food Science and Technology 40(1):223-227.

Keshani, S., Luqman Chuah, A. and Crossly, A.R. (2012). Effect of temperature and concentration on rheological properties pomelo juice concentrates. International Food Research Journal 19 (2):553-562. 
Keshani, S., Luqman Chuah, A., Nourouzi, M.M., Russly, A.R. and Jamila, B. (2010). Optimization of concentration process on pomelo fruit juice using response surface methodology (RSM). International Food Research Journal 17:733-742.

Kim, E. (2010). Relationship Between Viscosity and Sugar Concentration in Aqueous Sugar Solution Using the Stokes' Law and Newton's First Law of Motion. Vancouver: University of British Columbia Library.

Maskan, M. (2006). Production of pomegranate (Punica granatum L.) juice concentrate by various heating methods: color degradation and kinetics. Journal of Food Engineering72: 218-224.

Mohammadi sani, A., Hedayati, G. and Arianfari, A. (2013). Effect of temperature and concentration on some of rheological properties of melon juice. Journal of Food Science \& Industrial 34 (9):37-44.

Quek, S., Chok, N. and Swedlund, P. (2007). The physicochemical properties of spray-dried watermelon powders. Chemical Engineering and Processing 46:386-392.

Ramos, A.M. and Ibarz, A.( 1998). Density of juice and fruit puree as a function of soluble solids content and temperature. Journal of Food Engineering 35:57-63.

Shamsudin, R., Wan Daud, W.R., Takrif, M.S., Hassan, O. and Mustapha Kamal Abdullah, A.G.L. (2007). Influence of temperature and soluble solid contents on rheological properties of the Josephine variety of pineapple fruit (Ananas comsus L.). International Journal of Engineering and Technology 4:213-220.

Sharma, S.K., Lemaguer, M., Liptay, A. and Poysa, V. (1996). Effect of composition of the rheological properties of tomato thin pulp. Journal of Food Research International 29: 175-179.

Steffe, J.F. (1996). Rheological Methods in Food Process Engineering. East Lansing: $\quad$ Freeman 